\title{
A função narrativa de María de Regla em CECILIA VALdÉS de Cirilo Villaverde
}

\section{Francisco Eduardo Padula}

\section{Resumo}

Este trabalho tem como objetivo analisar a importante função narrativa que desempenha a personagem María de Regla na obra mais famosa de Cirilo Villaverde, Cecilia Valdés. Aparentemente secundária nos primeiros capítulos do romance, vamos nos dando conta de sua importância no decorrer da obra, especialmente nos capítulos VIII e IX da terceira parte quando relata às suas amas o porquê de Doña Rosa, mãe das jovens, mandá-la ao engenho La Tinaja. Faz alusão ainda, através de uma interessante técnica narrativa a qual não se inicia pelo início da história, à existência de outra meio-irmã que elas teriam. Essa meio irmã é justamente a personagem que dá título ao livro de Villaverde: Cecilia Valdes. Também assim, analisa-se o final da história quando María de Regla, ao querer ajudar seu marido que se encontrava preso, conta a verdadeira origem de Cecilia, jovem mãe que acabara de ter um filho de Leonardo, filho primogênito e dileto de Doña Rosa. Da resolução que toma a matriarca em casar seu filho e de sua morte no altar também há a interferência de María de Regla graças a uma interessante peripécia.

Palavras-chave: adultério; função narrativa; peripécia.

\section{Resumen}

Este ensayo ten como objetivo analizar la importante función narrativa que desempeña el personaje María de Regla en la obra más famosa de Cirilo Villaverde, Cecilia Valdés. Aparentemente secundaria en los primeros capítulos de la novela, nos vamos dando cuenta del importante rol de la esclava en el desarrollo de la obra, especialmente en los Capítulos VIII y IX de la tercera parte cuando relata a sus amas por qué Doña Rosa, madre de las jóvenes, la envía al ingenio La Tinaja. También hace alusión, por una interesante técnica narrativa en la cual no inicia por el principio de la historia, la existencia de otra media hermana que las jóvenes tendrían. Esa media hermana es el personaje que da nombre a la novela: Cecilia Valdes. Otrosí, se analiza el final de la historia cuando María de Regla, al querer ayudar a su marido que estaba preso, cuenta el verdadero origen de Cecilia, joven madre que había dado luz cuyo padre era Leonardo, hijo primogénito y preferido de Doña Rosa. De la resolución que toma la matriarca en casar su hijo y de su muerte en el altar, también hay la interferencia de María de Regla gracias a una interesante peripecia.

Palabras clave: adulterio; función narrativa; peripecia. 


\section{INTRODUÇÃO}

O objetivo deste trabalho é analisar a forma pela qual María de Regla, uma das personagens do romance Cecilia Valdés, é peça fundamental para o seu desenvolvimento, embora seu protagonismo não seja evidente à primeira vista. Também pretende estudar a participação de outra personagem feminina, Doña Rosa.

Para tanto, será necessário apresentarmos brevemente a obra.

Composto pela primeira vez em 1839 por Cirilo Villaverde, grande defensor do abolicionismo, mas nem por isso isento de preconceitos porque ao longo da leitura percebemos que o autor não escapa de muitas ideias pré-concebidas e desprovidas de qualquer fundamentação, como, na seguinte passagem: "Así es que, sin vergüenza ni reparo [a protagonista], a menudo manisfetaba sus preferencias por los hombres de lar raza blanca y superior, como que de ellos es de quienes podia esperar distinción y goces." (VILLAVERDE, 1981, p.41) ou na descrição de um dos amigos de Leonardo Gamboa: “...agregaba um color de tabaco de hoja que hacía dudar mucho de la pureza de su sangre" (VILLAVERDE, 1981, p. 67) ${ }^{1}$. O romance teria sua versão definitiva somente em $1882^{2}$. Grosso modo, a história tem como um dos seus focos a personagem que leva o nome da história, Cecilia Valdés, e seu amor incestuoso com Leonardo, meio irmão ${ }^{3}$, filho de um senhor de engenho, Dom Cándido Gamboa, também pai de Cecilia com uma mulata chamada Charito. A recém-nascida é separada de sua mãe em seus primeiros dias de vida para se evitar um possível escândalo, pois Dom Cándido era casado com Doña Rosa. Tal separação enlouquece Charito.

Surge o problema de amamentar o bebê. Nesse momento, é apresentada ao leitor María de Regla, escrava e promissora ama de leite, uma vez que seu filho recém-nascido morrera há pouco tempo de tétano. Citada rapidamente no primeiro capítulo da primeira parte tem-se primeiramente a impressão de se tratar de uma personagem secundária. Mas, à medida que o romance avança, fica claro que está faltando uma peça chave que elucide às personagens as muitas informações de que não dispõem, principalmente à Doña Rosa, matriarca da família Gamboa, e às filhas de Don Cándido. Essa peça é María de Regla. Desse modo, nos capítulos VIII e IX da terceira parte a ama de leite contará às filhas de Dom Cándido (e ao leitor) todos os detalhes de uma história a qual vai se revelando à Isabel o "...cuadro nada limpio ni edificante de la familia" Gamboa ${ }^{4}$.

Enfim, nos últimos capítulos da história, a escrava, tentando ajudar seu marido (Dionisio) que fora preso, decide contar à Doña Rosa a verdade sobre a paternidade de Cecilia e seu amor incestuoso com Leonardo. Aterrada, a matriarca determina casá-lo com outra importante personagem feminina da romance, Isabel Ilincheta, pretendente de longa data. Tudo correria bem se Cecilia não interviesse na história. Essa pede a um ajudante de alfaiate de nome José Dolores Pimienta - que sempre a amou - para matar a Isabel. No entanto, Pimienta "entende" a ordem ao contrário e mata Leonardo. 
Assim, Cecilia é presa como cúmplice da trama, Dionisio cumpre pena por longo tempo e Isabel interna-se em um convento.

Outros aspectos importantes nesta obra são a submissão à força da colônia pela metrópole, a economia açucareira, seus desdobramentos, etc. Esses temas não serão tratados diretamente neste trabalho.

Do exposto, veremos como se dá a função narrativa de María de Regla, empregada em princípio como ama de leite (objeto) e como ela cria (sujeito) um elemento tensivo ao longo do romance ao usar a informação de que dispõe quando conta a sua história e a de Cecilia para a filha dos Gamboa.

Por outro lado, outra personagem de destaque é Doña Rosa, a contrapartida de María de Regla. Embora disponha de muito poder, não possui a informação fundamental de que dispõe sua escrava e nem tato para confirmar suas suspeitas. Age ainda às escondidas de seu marido e manipula facilmente seu filho, Leonardo, a quem tem predileção especial.

\title{
1. O INÍCIO DA HISTÓRIA
}

A história da personagem que leva o nome do romance inicia-se quando seu pai visita a avó de Cecilia Valdés e lhe pergunta sobre o estado da mãe do bebê. A anciã lhe dá as piores notícias possíveis, pois efetivamente Rosario Alarcón estava louca: "- ¿Y qué tal la enferma? [Charito ou Rosario Alarcón]. La mulata sacudió la cabeza con aire todavía más triste y contestó con tres monosílabos: - ¡Ah!, muy mal”. (VILLAVERDE, 1981, p. 10).

Passam-se alguns anos e encontramos uma menina callejera a vagar pelas praças de Havana. Chama a atenção das pessoas sua beleza física precoce:

\begin{abstract}
Algunos años adelante (...) solía verse por las calles del barrio del Ángel una muchacha de unos once o doce años de edad, quien, ya por su hábito andariego, ya por otras circunstancias de que hablaremos en seguida, llamaba la atención general. (...) Las mejillas llenas y redondas y un hoyuelo en medio de la barba, formaban un conjunto bello, que para ser perfecto sólo faltaba que la expresión fuese menos maliciosa, si no maligna. (...) Pero de cualquier manera, tales eran su belleza peregrina, su alegría y vivacidad, que la revestían de una especie de encanto, no dejando el ánimo vagar sino para admirarla y pasar por las faltas o por las sobras de su progenie. (...) La chica crecía gallarda y lozana, sin cuidarse de las investigaciones y murmuraciones de que era objeto (VILLAVERDE, 1981, p. 16-7).
\end{abstract}

Com o correr das páginas, personagens são apresentadas. Como todo romance, algumas personagens são importantes e outras não. Os protagonistas do romance são: a personagem que leva o nome da obra, Cecilia Valdés; Leonardo Gamboa, meio-irmão por parte de pai de Cecilia; Don Cándido Gamboa, patriarca da família Gamboa; Doña Rosa Gamboa, sua esposa; Seña Josefa, avó de Cecilia; Isabel Ilincheta, pretendente de Leonardo, 
María de Regla, escrava e ama de leite de Adela; Dionisio, marido de María de Regla e também escravo cuja principal função era ser cozinheiro dos Gamboa e José Dolores Pimienta, ajudante de alfaiate, músico e apaixonado por Cecília.

Nas primeiras páginas do romance, os leitores se dão conta de que Don Cándido é também pai de Cecilia Valdés, embora essa não o saiba. Tal constatação se dá no segundo capítulo do romance:

- Papá, papá - dijo la mayor de las señoritas (Antonia) dirigiéndose a un caballero que estaba recostado en un sofá a la derecha del estrado -. Papá, ¿ha visto V. niña más preciosa?

- Ya, ya - contestó el padre casi sin volver el rostro -. Dejadla en paz -. Pero apenas salieron esas palabras de sus labios, reparó Cecilia, y entre admirada y reída, dijo: ¡Ay! Yo conozco a ese hombre que está acostado.

Este, por debajo de las manos, con que se sombreaba la frente, le echó una mirada fiera, en que iban pintados su mal humor y disgusto. En seguida se levantó y dejó la sala, sin decir más palabra. Extraño es en verdad que sólo este hombre no sintiese simpatía por la linda callejera (VILLAVERDE, 1981, p. 18).

Don Cándido tem quatro filhos legítimos: um rapaz e três moças. Por uma ironia do destino, a protagonista do romance se apaixona perdidamente por Leonardo, o primogênito da família Gamboa. Embora Don Cándido tente evitar essa união com o correr do tempo e dos acontecimentos nasce uma menina.

A matriarca, Doña Rosa, desconfia da fidelidade de seu marido desde o momento em que esse mandou María de Regla amamentar uma filha ilegítima de um seu amigo. Como Don Cándido jamais revelou-lhe seu nome, a matriarca deduziu corretamente que era seu marido o pai de Cecilia, embora carecesse de provas. Ainda assim, Doña Rosa sente ódio mortal por sua escrava e, por esse motivo, a escrava é desterrada ao engenho La Tinaja. Segundo a matriarca, María de Regla desobedeceu às ordens de seus amos, isto é, amamentou simultaneamente a Adela e a sua própria filha, chamada Dolores, ambas nascidas em datas próximas. Então, privada dos filhos e do marido e sendo castigada de modo cru, María de Regla fará de tudo para voltar a Havana.

Também é importante destacar a participação das personagens femininas na Terceira Parte do romance (parte que mais me deterei a analisar neste trabalho), pois sua preponderância é quase absoluta: temos o protagonismo de Isabel no engenho La Luz em seus dois capítulos iniciais é a mesma personagem quem salva um velho negro porteiro da ira de Leonardo no início do capítulo seguinte quando da entrada no engenho La Tinaja, propriedade da família Gamboa. Por sua vez, Doña Rosa dá indulto a muitos escravos que haviam fugido, apesar da ira de D. Liborio, capataz que possui uma espécie de carta branca por parte de Dom Cándido para tomar decisões, fossem elas justas ou não, etc ${ }^{5}$. Tem razoável êxito contrapondo-se à figura de seu marido e de seu capataz quando manda tirar as correntes 
de muitos escravos capturados; dá-lhes roupas e até uma esposa para um deles (VILLAVERDE, 1981, p. 292). Será Doña Rosa, enfim, que cederá aos rogos de Adela para que María de Regla volte à Havana.

Quanto à ama de leite, essa terá papel de destaque, pois o narrador dará sua voz a ela de modo que conte aos leitores e, principalmente, às mulheres que se encontravam no quarto de Adela, detalhes de sua vida.

Curiosamente, a única mulher que não age nessa parte do romance é a protagonista, Cecilia Valdés. E nem poderia agir, pois está em Havana, longe dos acontecimentos, mas sua ausência aqui não causa grandes problemas no desenvolvimento da história.

\section{A FunÇão narrativa de María de Regla e o problema da laCtânCia}

Por função narrativa deve-se entender o papel que a escrava dos Gamboa desempenha na trama do romance, de tal forma que consegue mobilizar a atuação de outras personagens, como por exemplo, Adela, Carmen, sua irmã, e sua própria ama, Doña Rosa, embora com relação a essa seu escopo de atuação seja nulo quando se trata de favorecer sua precária condição de escrava. À Adela não lhe é difícil suscitar compaixão pela escrava que a amamentou, pois a moça recebe constantes notícias dos péssimos tratos que sofre a ama no engenho. Também assim, a jovem não consegue entender o ódio que devota sua mãe à María de Regla a qual comenta: "(...) La muy perra", "Para mí ella ha muerto!", "No sé yo que la maltraten más que merece!" (VILLAVERDE, 1981, p. 175), etc. Tal banimento jamais é explicado claramente às personagens, principalmente à Adela. Se a escrava a amamentou por longo tempo, lhe dedicou cuidados constantes em detrimento mesmo de sua própria filha, por que Doña Rosa a odeia tanto a ponto de desterrá-la? ${ }^{6}$ Não obstante, o principal argumento da matriarca contra sua escrava embasa-se em uma suposta desobediência: amamentar simultaneamente Adela e Dolores. "Prohibiósele explícitamente a María de Regla el dividir sus caricias y el tesoro de su seno entre las dos niñas, siquiera el tomarlas juntas en brazos." (VILLAVERDE, 1981, p. 172). A proibição imposta María de Regla baseava-se na crença segunda a qual uma mulher não poderia amamentar ao mesmo tempo duas crianças. Karen Monteleone nos informa que, "Según Gabrielle Palmer, era una falacia común que una mujer no podía amamantar más que a un niño sin disminuir la calidad y la cantidad de su leche. Estas creencias sobre la conservación de la leche conducían a una serie de tabúes." 7

Mas Dolores é a companheira de Adela, sempre está a seu lado e a serve fielmente. Qual um fiel animal, até dorme ao seu lado, no chão. Tal contradição por parte da matriarca só faz aumentar esse páthos que a menina sente pela escrava.

Dados esses impasses, poder-se-ia pensar em uma possível solução para a questão racial no romance (afinal, Doña Rosa não poderia continuar tão irascível para com sua escrava), mas as palavras de Seña Josefa à Cecilia (quase na metade do romance) 
admoestando-a que a união com Leonardo seria impossível, também valem para o leitor:

- Diría que ese es un sueño irrealizable, un disparate, una locura. En primero lugar él es blanco y tú de color, por más que lo disimulen tu cutis de nácar y tus cabellos negros y sedosos. En segundo lugar, él es de familia rica y conocida de Habana, y tú pobre de origen oscuro... (VILLAVERDE, 1981, p. 190).

Como se vê, longe de uma integração entre as três raças (Leonardo [criollo], Cecilia [mulata] e María de Regla [a negra escrava]) prefigura-se a impossibilidade de união dada as condições sócio-políticas de uma Cuba ainda colônia de Espanha. Juan G. Gelpí, em seu artigo (op. cit.) nos esclarece:

(...) en la novela de Villaverde no hay una historia de amor que represente de manera alegórica la unificación nacional. Hay, en cambio, una historia de amor que termina en una especie de disolución nacional. Se puede alegar que en la Cuba del siglo XIX - colonia política, además de sociedad esclavista - difícilmente se podían escribir novelas en las que se celebrara una unidad nacional que no existía (...) Villaverde, em cambio, presenta una anti-utopía nacional (p. 56).

Ainda com relação à delicada questão da amamentação pelas escravas em uma colônia escravista no início do século XIX, Christina Civantos, em seu artigo "Pechos de leche, oro y sangre: las circulaciones del objeto y el sujeto en Cecilia Valdés"8, analisa uma passagem na qual o narrador fala sobre aquilo que denomina "la leche de la esclavitud". Lemos no romance:

Porque ellas, aunque criadas a la leche de la esclavitud, como tiernas flores que abrían sus pétalos a los primeros rayos del sol de la vida, bien podían exclamar con el orador latino, bumani nihil a me alienum puto." [Nada do que é humano me é estranho]. (na edição da Biblioteca Ayacucho (VILLAVERDE, 1981, p. 303).

\section{E agora o comentário de Civantos:}

La frase "la leche de la esclavitud" se puede entender de por lo menos dos maneras. Primero, si "la leche" se lee con sentido metafórico, como lo que nutre a uno desde la infancia a través del contacto íntimo, se entiende que estas señoritas han tenido contacto estrecho con el sistema esclavista desde pequeñas. Por esta razón se introduce con un "aunque": se asume que el que se ha criado en este sistema de opresión y explotación lo acepta y no llora al ver sus resultados terribles. Pero, si se lee "la leche" y "la esclavitud" metonímicamente como "las esclavas" (tomando la institución por el agente: la esclavitud por las que producen la leche dentro de la esclavitud), llegamos a la razón por la cual las señoritas sí sentirían compasión por los esclavos. Este es el segundo peligro que representa la nodriza, además de desplazar a la madre "uterina", deshace las jerarquías sociales, no sólo la esclavitud, sino las jerarquías raciales en sí" (CIVANTOS, 2005, p. 507-8).

Acrescentemos que a primeira leitura, isto é, a leitura que legitima a escravidão, valeria 
para Leonardo e Antonia (a segunda filha dos Gamboa e a mais velha da progênie feminina dessa família), pois ambos são implacáveis para com seus escravos. Por exemplo: no caso do escravo Aponte, ameaçado por Antonia após um incidente entre sua carruagem e a carruagem conduzida por outro escravo no início do primeiro capítulo da segunda parte ("...y la mayor de ellas amenazó [isto é, Antonia] repetidas veces al calesero [Aponte] con un fuerte castigo si no desistía de la riña y atendía a los inquietos caballos" (VILLAVERDE, 1981, p. 103) e, efetivamente, castigado de maneira rigorosa por Leonardo (VILLAVERDE, 1981, p. 144) após o mesmo escravo não comparecer com sua carruagem para levá-lo com seus amigos às suas casas quando do término de uma festa. Quando do castigo de Aponte, inicia Leonardo: “- Suelta la tarima - le ordenó éste con voz bronca por la cólera -, arrodíllate y quítale la camisa. (...) Y sin más ni más empezaron a llover zurriagazos en las espaldas del infeliz esclavo. Se retorcía, porque los golpes los descargaba un brazo vigoroso..." (VILLAVERDE, 1981, p. 122). Então, dessas ações dos filhos mais velhos dos Gamboa e, em especial, da surra que aplicou Leonardo ao seu escravo, a primeira leitura analisada por Civantos (a de que legitima a escravidão) valeria ao primogênito e à Antonia. Daí a conclusão do narrador, ao terminar o Capítulo V da Segunda Parte, segunda a qual a escravidão e suas implicações (como os castigos) seriam algo absolutamente natural:

Después de eso [dos fortes açoites que aplicou Leonardo ao seu escravo], ¿cuál de los dos, la víctima o el verdugo, encontró primero reposo en la cama? (...) e imposible que lo entiendan en toda su fuerza aquellos que no han vivido en un país de esclavos. (VILLAVERDE, 1981, p. 144).

Para as filhas mais novas dos Gamboa e para Isabel Ilincheta, parece valer a leitura embasada na metonímia, isto é, o leite produzido por causa da instituição escravidão gerando assim graves distorções nas relações entre seres humanos.

Assim, para quem lê o romance, fica fortemente sugerido que o desterro de María de Regla deve-se também à suspeita que tem Doña Rosa quando da amamentação de "uma recém-nascida" cuja ama fora sua escrava e cujos serviços foram "pagos" por um "amigo" de Don Cándido. No entender de Doña Rosa, seria uma espécie de cumplicidade entre amo e escrava. Dessa maneira, querendo vingar-se de Don Cándido, vinga-se também da ama de leite, desterrando-a e impondo-lhe duras penas ${ }^{9}$. Mas - sabemos - tal vingança atinge somente María de Regla e não a seu amo. Prova disso, é o desdém que esse sente quando sua escrava tentara falar-lhe: " - Vinieron unas Pascuas el amo y el niño Leonardo, mas ninguno de los dos quisieron verme ní oírme tampoco" (ibid.). Vemos, portanto, que a ação que exerce María de Regla para tentar convencer Doña Rosa de sua inocência é nula.

Voltemos à María de Regla. Além da menção no início da obra feita por Don Cándido, em um diálogo com Seña Josefa, constata-se que a escrava desaparece por muitas páginas. Em 
princípio, parece ser uma personagem necessária ao contexto de uma Cuba escravista, mas que não exerceria papel relevante na obra. Quase nos esqueceríamos dela se não fosse por algumas alusões da própria Doña Rosa a seu marido no decorrer da história, como no Capítulo VII. Em uma das intermináveis discussões a respeito de Leonardo, a matriarca insinua sobre sua infidelidade a tal ponto que esse lhe pergunta:

- ¿Sabe que yo haya pecado?

- Talvez lo sepa.

- Si V. no se lo ha contado...

- No hay necesidad de que yo le enseñe cosas malas. Sería madre desnaturalizada si tal hiciera. Pero él no es ningún tonto, y luego fue demasiado público, escandaloso lo de María de Regla. (VILLAVERDE, 1981, p. 56).

Mas será somente no Capítulo IX da Segunda Parte que saberemos um pouco mais sobre a escrava:

María de Regla, mencionada al principio de esta historia, tuvo a Dolores de su unión legítima con Dionisio el cocinero, quince años antes de la época actual. Contemporáneamente tuvo doña Rosa a Adela, su hija menor, la cual entregó a María de Regla para que se lactase, por no sentirse ella en condiciones para desempeñar por entonces aquel, el más dulce de los deberes de madre. (...) Prohibiósele explícitamente a María de Regla el dividir sus caricias y el tesoro de su seno entre la dos niñas (...) Pero, (...) así que siempre que las otras esclavas proporcionaban la ocasión, tarde de la noche y fuera de lo alcance de la vista de los amos, se ponía ambas niñas a los pechos y las amamantaba con imponderable delicia. (...) Al cabo, atraída una noche doña Rosa por el llanto de su hija, sorprendió a la nodriza dormida entre las dos niñas (...). ¿Qué hacer en aquellas circunstancias? (...) Tan perpleja estaba que consultó a su marido (...) [e esse] aconsejó la prudencia y el disimulo hasta ocasión más oportuna (...). De cualquier modo, así continuaron las cosas por año y medio más, al cabo de cuyo tiempo, el día menos pensado, se le ordenó al Mayordomo echara por delante a la criandera y la embarcara a bordo de una goleta que hacía viajes de La Habana al Muriel, dejándola en el ingenio La Tinaja, bien recomendada al Mayoral. (VILLAVERDE, 1981, p. 172-3).

Teremos de esperar mais de cem páginas para conhecer um pouco mais sobre essa interessante personagem. Finalmente, nos Capítulos VIII e IX da Terceira Parte, María de Regla atuará de forma direta no romance.

Assim, estando os Gamboa e Isabel Ilincheta no engenho La Tinaja para passar as Páscoas, uma pequena escrava dá o recado à Adela dizendo-lhe que María de Regla gostaria de lhe falar. Marca-se, então, um encontro e espera-se pela escrava para contar seu sofrimento e o verdadeiro motivo de seu desterro.

\section{María de Regla ATUA}


Quando dizemos da atuação de María de Regla queremos indicar que a escrava revelará fatos às filhas dos Gamboa e à Isabel Ilincheta cujo conteúdo até então desconheciam. Na verdade, algumas informações passadas pela escrava não foram mencionadas pelo narrador em sua breve descrição da personagem (cf. p. 172-3), como por exemplo, os constantes castigos (em verdade, verdadeiras surras) que levou dos dois capatazes (Bocabajo, v.g. -10), o primeiro com o sugestivo nome de D. Anacleto Puñales e o segundo, mais terrível ainda, D. Liborio ${ }^{11}$. Ambos desejavam-na sexualmente, mas como essa não cedia "allá iba el cuerazo" (VILLAVERDE, 1981, p. 316), especialmente por parte de último capataz ${ }^{12}$.

Antes de contar a história da amamentação de Cecilia, a escrava relata sua trágica vida no engenho La Tinaja. É de se notar que primeiro conta seu sofrimento e, após, o porquê desse sofrimento. $\mathrm{O}$ verdadeiro motivo de seu desterro, qual seja, o de ter amamentado Cecilia, somente será citado em capítulo à parte de sua "autobiografia". Assim, iniciar por uma narração em primeira pessoa é uma técnica que o narrador utiliza para captar a compaixão das personagens (e também dos leitores), a chamada captatio benevolentiae, porque, ao contar sua vida, torna-se ela mesma protagonista nessa parte do romance.

É importante atentarmos que a palavra é dada não somente a uma mulher mas, principalmente, a uma escrava. Juan G. Gelpí em "El discurso jerarquico en Cecilia Valdés" nota que todas as personagens que não possuem instrução escolar são marcadas por aspas. Mas, no que tange à escrava, isso quase não ocorre ${ }^{13}$. Desse modo, a escrava se distancia daquelas personagens e, além disso, no que se refere a sua participação no romance, é uma figura mediadora e transgressora. O crítico acrescenta ainda que "les da [María de Regla] el pecho a su propia hija negra Dolores, a la mulata Cecilia Valdés y a la hermana blanca de ésta, Adela Gamboa. Por lo tanto, es madre figurada o de leche de toda la gama racial que se representa en la novela" (p. 52). Desse modo, não pode deixar de ter um significado especial para a filha mais nova dos Gamboa. Também o tem para Doña Rosa, mas por motivo oposto porque, como se sabe, a matriarca a odeia.

Ainda assim, María de Regla poderia ser classificada como "a mãe preta” de Adela, pois dormia e acordava com ela. Após ser desterrada, Dolores, sua filha, substituirá a mãe em boa parte de suas funções. Também é importante frisar que a relação ama de leite com as crianças se estendeu para muito além do fim da escravidão. Darei um exemplo próximo à nossa realidade. No documentário Babás ${ }^{14}$, vemos que até os dias de hoje as babás são requisitadas por muitos casais que não têm tempo suficiente para cuidar de seus filhos. Geralmente, quem cuida das crianças brancas são mulheres negras embora haja exceções. Desse modo, mesmo que a escravidão tenha acabado, a relação entre babás e patrões continua até hoje sendo que as babás continuam a trabalhar arduamente.

Mas voltemos aos gestos da escrava: quando entra no quarto no qual the esperavam, não pede licença; antes, vai direto à Adela, abraça-a e a levanta com "sus robustos brazos" 
chorando e beijando-a copiosamente. Euforicamente, acrescenta: "¡Mi cielo! ¡mi lindura! ¡mi pimpollo! ¡mi hija idolatrada" (VILLAVERDE, 1981, p. 311). Ajoelha-se então e chora no colo de sua pequena ama. É como se estivesse atuando a uma platéia sabendo que dessa atuação depende sua vida: se atuar bem, haverá alguma chance de ser favorecida, caso contrário poderá permanecer o resto de sua vida ali, pois María de Regla sabe que Adela é nova e ainda muito suscetível às sugestões ${ }^{15}$. Vemos, portanto, como a escrava lança mão dos meios que tem para tentar captar as simpatias das filhas de Doña Rosa.

Após dita cena pautada mais no espetáculo (gestos) do que no discurso (lógos), María de Regla conta brevemente sua vida na cidade de Jaruco quando se casou com Dionisio; da morte de seu antigo dono e sua venda juntamente com seu esposo para os Gamboa (VILLAVERDE, 1981, p. 313). Relata brevemente sua estadia em Havana para, em seguida, ser desterrada no engenho.

Compõe, assim, a tessitura de sua própria tragédia. Cabe aqui uma pequena digressão acerca da tragédia clássica. Como se sabe, esse gênero literário é exclusivo da Grécia do século $\mathrm{V}$ a.C. tendo como sua primeira obra Os Persas de Eurípedes. Um dos seus principais constituintes é a peripécia analisada por Aristóteles. Essa pode ser tanto para a dita quanto para a desdita, ou nas palavras do filósofo “(...) de felicidade ou infelicidade” (Poética, VI, \ 16). No caso de María de Regla, após a morte inopinada de seu primeiro amo, Conde de Santa Cruz (cidade de Jaruco), tudo muda para pior, pois até então, como lembra "(...) nos casamos y fuimos [María de Regla y Dionisio] los más felices esposos del mundo" (VILLAVERDE, 1981, p. 313).

Também é importante mencionar que a história de María de Regla parece estar inserida em outra história maior, a da própria Cecilia Valdés.

Esta inclusão faz parte da estrutura e lógica da obra. No que se refere à protagonista, é importante salientar que na primeira versão deste romance (1839), Villaverde alude a uma ate (crime hediondo praticado por alguém o qual passa a ser punido até a quinta geração) cometida em algum momento na linhagem não de Leonardo, mas da moça: “...y la infeliz Cecilia, hechura del crimen, su estrella la arrastraba al pecado por el mismo camino que arrastró a su madre, herencia o vínculo que frecuentemente vemos trasmitirse de padres a hijos hasta la quinta generación" 16 . Cabe lembrar que muito provavelmente a bisavó de Cecília, mencionada rapidamente no início do romance, "escuálida, imagen de la muerte, cuya cabeza blanca contrastaba com el ébano de su cuello largo y huesoso" (VILLAVERDE, 1981, p. 13) seria, nessa lógica, a primeira da estirpe; após, Seña Josefa, a avó de Cecília; depois, Rosario Alarcón, a mãe da protagonista; em seguida, na quarta geração, a própria Cecilia Valdés e por fim sua filha (não nomeada) fechando o ciclo. Chama à atenção o contraste da descrição da bisavó de Cecilia de "cuello de ébano" com a protagonista "que sin dejar de ser sanguíneo [seu rosto] había demasiado ocre en su composición. (...)” “... y bien podia asegurarse que allá en la 
tercera o cuarta generación estaba mezclada con la etíope" (VILLAVERDE, 1981, p. 17). Portanto, parece que mesmo com as substanciais mudanças efetuadas ao longo de quarenta anos até a feitura final do romance, a estrutura da tragédia permaneceu nessa obra.

Quanto ao relato de María de Regla, esse não é cronológico. Uma narração que obedecesse ao tempo como no calendário iniciaria-se em Jaruco para, depois, findar-se no engenho. Mas María de Regla não faz nada disso. Habilmente descreve seu martírio pormenorizadamente suscitando assim nova comoção às senhoritas. Mas parece que a escrava sabe que somente palavras não são suficientes para convencer as céticas visitas ${ }^{17}$. É preciso dar mostras materiais. Logo após mencionar os constantes castigos, María de Regla pede à Adela para tateá-la:

" - Tiente, niña, tiente aquí en los hombros y las paletas. Meta la mano".

La deslizó Adela, con cierto recelo, por entre la piel y las ropas de la negra y las retiró precipitadamente porque sus dedos de rosa fueron tropezando con verdugón tras verdugón, trazados en todos sentidos, a la manera de los camellones del terreno recién arado [...]. Doña Rosa e Isabel vertieron más de una lágrima de simpatía por la martirizada esclava. (VILLAVERDE, 1981, p. 316).

Somente após almejar o que pretendia, María de Regla relata com mais detalhes sobre seus anos em Havana e qual o aparente motivo de seu desterro. Aproveita a ocasião para revelar o que realmente gostaria de dizer sobre Cecilia Valdés. Mas, para isto, é preciso um capítulo especial (Capítulo IX, Parte III), ou de outro modo: sugerir sobre a paternidade da neta de Seña Josefa, dos ciúmes de Doña Rosa, sua ira e sobre a referida amamentação e consequente desterro da escrava.

\section{A OUTRA História}

María de Regla tem um primeiro filho que, por desgraça, morre de tétano. É-lhe incubida então por Don Cándido a amamentar outra criança. O estranho de tudo é que não se tratava de um amigo que morasse em uma residência por todos conhecida. Tal amigo sempre foi uma incógnita e a menina encontrava-se em uma casa especial, em verdade, na Casa Cuna, mais especificamente, na casa dos expostos. Cito aqui Antonio de las Barras y Prado, um jovem espanhol que tentou a vida em Havana no fim do segundo lustro da década de 1840 e início de 1850. O jovem Barras y Prado escreve umas memórias que após sua morte foram publicadas por seu filho, Francisco. Seu relato é muito interessante, pois tenta nos descrever a cidade de Havana, seus quartéis, igrejas, suas leis, costumes e a situação dos escravos de forma mais objetiva que lhe era possível. Em muitas passagens de seu livro, principalmente quando se refere aquelas que falam de lugares, parece que é o próprio Villaverde quem está a narrar dada a semelhança na narração. Por exemplo, o narrador ao referir-se à protagonista quando levada para a casa dos expostos, diz: "Es preciso que la chica lleve un nombre, nombre de que no 
tenga que avergonzrse mañana, ni esotrodía, el de Valdés, con que quizás haga un buen casamiento." (VILLAVERDE, 1981, p. 12), Barros y Prado (1925) afirma que

[L]os mulatos prohijados por la Casa Cuna, que toman el apellido Valdés en memoria del Obispo Fr. Jerónimo Valdés que la instituyó, salen, por privilegio, ennoblecidos, es decir, pueden usar Don como los blancos y gozan de todos los beneficios y prerrogativas de éstos, incluso el de desempeñar destinos públicos, sin que nadie pueda decirles la palabra considerada ultrajante de mulato, so pena de exponerse a una querella por injuria (BARROS Y PRADO, 1925, p. 113). ${ }^{18}$

Daí a informação subentendida de Don Cándido. Como se vê, Villaverde opera com lugares e instituições reais em seu romance o que o torna ainda mais verossímil.

Assim, não fosse por María de Regla, as filhas de Don Cándido jamais saberiam da ida da escrava à Casa Cuna para amamentar outro bebê por ordem de seu pai e, depois, continuar amamentando-a na própria casa de Seña Josefa, tudo a cargo do patriarca. Aqui a informação da escrava se revela como algo sugerido sobre a paternidade do bebê, pois as filhas de Don Cándido poderiam se perguntar qual a preocupação de Don Cándido em deslocar sua escrava a um lugar onde eram deixadas as crianças expostas para a casa de uma humilde senhora.

Quando chega à casa de Seña Josefa, María de Regla se dá conta de que a mãe dessa criança enlouquecera por completo e, depois, constata pelo orifício da fechadura da porta que quem estava na janela a tratar com a avó do bebê "parecia" ser seu próprio amo, Don Cándido Gamboa: "Pero me figuré, niñas que el caballero que vi al postigo de la ventana besando a la niña era... el amo. Se parecía mucho” (VILLAVERDE, 1981, p. 322).

Escandalizam-se suas filhas, mas não tanto a ponto de não levarem em consideração o que a escrava dissera; principalmente Carmen, a "quien la diplomacia de ama empezaba a ejercer su imperio sobre la pasión de la hija" (VILLAVERDE, 1981, p. 322). Fica tudo sugerido, ou como se diz coloquialmente, o dito pelo não dito. É de se notar que, quanto à conduta de seu amo, María de Regla jamais afirma categoricamente às suas filhas que ele seria o pai de Cecilia, mas apenas alude (Se parecía mucho. "Se parecia, mas não digo que fosse", complementaria). A alusão advém do fato de ser escrava. Jamais María de Regla poderia afirmar que era Don Cándido o homem que estava junto à janela. Que seria portanto ele o pai legítimo, adúltero, ainda que não quisesse reconhecer a recém-nascida. Afirmar isso seria perjúrio contra seu amo, e escravos que assim o faziam sempre eram castigados de forma rigorosa. A consequência disso seria mais um castigo (talvez outro bocabajo) e a confirmação de seu desterro para sempre no engenho La Tinaja. No entanto, sua alusão é tão sugestiva que não deixa margem a dúvidas. Portanto, graças a engenhosas alusões, María de Regla afirma negando. Um exemplo. Na primeira intervenção de Don Cándido, diz inopinadamene à sua escrava: "[...] te he alquilado [...] para dar de mamar a uma niña de algunos días de nacida. !Ea con que estar lista para después del almuerzo!” (VILLAVERDE, 1981, p. 317). Vemos, assim, 
como a escrava vai aos poucos informando a verdadeira história sobre a paternidade de Cecilia às filhas de Don Cándido. É como se dissesse: " - Vejam, meninas, e especialmente Adela: eu estou aqui porque seu pai teve uma filha não reconhecida e me pôs a amamentá-la. Por isso sua mãe me tem um ódio visceral e usou a desculpa por ter lhe desobedecido quando amamentei também a minha filha sendo também sua ama de leite."

Cabe acrescentar que Don Cándido tenta proteger sua filha natural não reconhecida, mas antes dessa preocupação outra se lhe impõe: a de ser descoberto por sua esposa. De fato, sempre que o patriarca via Cecilia, ainda criança, a andar sozinha na rua, ameaçava-lhe tentando com isso uma espécie de admoestação. Nas palavras de Cecilia: “(...) me dice callejera, perdida y muchas cosas. ¡Ah! Y dice que mandará a los soldados que me cojan y me lleven a la cárcel. ¡Qué sé yo cuánto más!” (VILLAVERDE, 1981, p. 24). Assim, agindo dessa forma, imaginava que estava protegendo sua filha. Mas veremos adiante que essa preocupação é inerte quando Doña Rosa agirá para castigar a Cecilia.

No fim desse relato surge Doña Rosa e a escrava atira-se a seus pés implorando perdão pelas faltas cometidas. Volta-se ao espetáculo comandado por gestos desesperados. Quanto à Adela, essa abraça sua mãe, pois estava demasiada comovida com a história, mas não Carmen e as demais mulheres. Nenhuma delas intercederá pela escrava como o faz Adela. Assim, María de Regla consegue mobilizar alguém que, se não fosse de todo querida por Doña Rosa (como se sabe, Leonardo é seu filho preferido), ao menos não seria desprezada por ela nesse contexto. A ama de leite tem plena ciência que jamais conseguirá demover Doña Rosa falando-lhe diretamente. Então, mobiliza Adela, suscitando-lhe compaixão para que esta interceda por ela. Em verdade, esse perdão é apenas uma trégua, uma espécie de armistício de Doña Rosa à sua escrava.

Desse modo, a escrava narra quatro grandes tópicos: a) dos castigos no engenho La Tinaja; b) de sua vida em Havana antes do nascimento de Cecilia Valdés; c) da estranha história da amamentação daquele bebê por encargo de Don Cándido e d) da amamentação de Dolores e de Adela e, por tal motivo, do pretexto desterro ao engenho.

Pelo exposto, podemos depreender que María de Regla inverte o tempo narrativo nos dois primeiros tópicos, dando ênfase no engenho (por lhe interessar) e respeita as sequências temporais para os itens c) e d) ainda que sua narração não seja apenas um simples contar de fatos, mas antes envolve o pai das moças que ouviam atentamente sua história, pois estavam também implicadas nela.

\section{María de Regla revela a Verdade À Doña Rosa}

No Capítulo VII da quarta parte María de Regla, em uma tentativa de aliviar a pena que pesava sobre seu marido, a de ter assassinado a Tondá porque aquele fugira enquanto seus 
amos estavam no engenho La Tinaja, conta à Doña Rosa quem é o verdadeiro pai de Cecilia Valdés. É a última vez que seu nome é mencionado no romance.

Seu objetivo, mais uma vez, não é alcançado. Ou, para usar de uma metáfora, erra o alvo: se queria beneficiar seu marido com sua revelação, tudo o que faz é desencadear uma sucessão de tragédias.

É forçoso fazer aqui outra digressão. Sabemos a distância temporal em que estão separadas as obras de Villaverde e Édipo Tiranos de Sófocles e de suas diferenças estruturais, mas a coincidência dos acontecimentos no que tange à ação das personagens em Cecilia Valdés parece coadunar, ao menos em parte, com um modelo de tragédia recomendado por Aristóteles. Isso explicaria porque María de Regla não poderia imaginar que, de sua revelação, haveria uma série de consequências funestas para as personagens. Parece que a escrava comete a conhecida hamarthía, isto é, um erro que leva a peripécias, no caso, à morte de Leonardo e a prisão de Cecilia por cúmplice de seu assassinato. Na referida obra de Sófocles, o estagirita observa: "Assim, no Édipo, o mensageiro que viera no propósito de tranquilizar o rei e de libertá-lo do terror que sentia nas suas relações com a mãe, descobrindo quem ele era, causou o efeito contrário" (Poética, XI, \60). Acrescentemos à nossa observação a de Roberto González Echevarría em seu artigo "España en Cecilia Valdés”

El incesto desplaza el conflicto político entre España y Cuba al ámbito mítico, y hasta sugiere en el fondo un juego casi abstracto entre lo mismo, lo distinto y lo parecido. El final de la novela es, consecuentemente trágico; los relatos míticos se dan próximos a la tragedia. La abuela de Cecilia muere en el hospital, su madre enloquece, Cecilia termina confinada por orden judicial, concertada por don Cándido, y da a luz a una hija de Leonardo, sugiriéndose el inicio de otro ciclo - otra vez mítico -. Pimienta asesina a Leonardo de una puñalada el día de su boda con su prometida blanca y rica, Isabel Ilincheta, matrimonio que iba a cimentar y ampliar la fortuna y el estatus de los Gamboa. Dado el parecido entre ambos se trata de una suerte de fratricidio. ${ }^{19}$

Sabemos que a escrava opera sobre outras personagens, como Doña Rosa, por exemplo, mas essa nunca age conforme a escrava prevê. De esperar alguma vantagem de tão importante revelação (qual seja, a de que Cecilia é meio-irmã de Leonardo), assombra Doña Rosa de tal modo que enfim se da conta "del abismo a que había empujado a su hijo" (VILLAVERDE, 1981, p. 401) forçando-o a casar-se com Isabel. Pouco importa à matriarca sobre o destino de sua escrava ou de Dionisio. Obcecada por Leonardo, tenta remediar os acontecimentos, mas essa nova intervenção de Doña Rosa só fará com que Cecilia se transforme de moça cordata em uma pessoa cuja conduta não pertence a um ser racional:

No faltó quien comunicara a Cecilia la nueva del próximo enlace de su amante con Isabel Ilincheta. Renunciamos a pintar el tumulto de pasiones que despertó en el pecho de la orgullosa y vengativa mulata. Baste decir que la oveja, de hecho, se transformó en león" (VILLAVERDE. 1981, p. 402). 
Isto é, se até aqui a protagonista também não obteve êxito em alcançar o que desejava, agora conseguirá ao menos impedir o casamento, embora não da forma como imaginava. Sabemos que Pimienta, assassina a Leonardo "entendendo" erroneamente o pedido de Cecilia para assassinar Isabel.

Desse modo, ao revelar sobre a paternidade de Cecilia à Doña Rosa, María de Regla espera obter vantagem para Dionisio que se encontrava preso pelo assassinato de Tondá. De fato, influi sobre a matriarca, mas no sentido oposto ao esperado. Continuando a pensar somente em Leonardo, tudo que a senhora Gamboa faz é arranjar o casamento entre seu primogênito e Isabel Ilincheta, pois se ela mesma havia incentivado a união entre Cecilia e Leonardo, agora, mudando radicalmente de idéia, acelera a união entre Leonardo e Isabel. Nada mais. Dioniso continuará preso ${ }^{20}$. Mas esse desejo cego da matriarca desencadeará outras ações de personagens de forma independente e totalmente fora do controle de Doña Rosa. Como acabamos de assinalar, Pimienta, por exemplo, "entende" erroneamente o pedido de Cecilia e lhe assegura que dito casamento não se efetuará:

\footnotetext{
- Pues cuente mi Celia que no se efectuará [o casamento entre Leonardo e Isabel] Sin más se desprendió él de sus brazos y salió a la calle. Cecilia, a poco, con el pelo desmadejado y el traje suelto, corrió a la puerta y gritó de nuevo:

- ¡José Dolores! José Dolores! ¡A ella, a él no!

Inútil advertencia. El músico ya había doblado la esquina de la calle de las Damas (VILLAVERDE, 1981, p. 402).
}

Talvez querendo mais uma vez vingar-se em seu marido, Doña Rosa vinga-se em Cecilia e esta é presa como cúmplice de tal assassinato. A inércia e ambiguidade da conduta de Dom Cándido em não defender sua filha e o destino de sua neta chamam à atenção. Se no início do romance, o patriarca fez tudo o que julgava necessário para proteger sua filha natural, nas páginas finais da história não intervém por sua filha. Ao contrário: permite a Doña Rosa descarregar todo seu ódio na moça, talvez porque a própria protagonista tenha se transformado em um "león". Acrescente-se a isso, o preconceito sobre os negros e mulatos predominante na época.

Também assim, o fim repentino do romance, através do silêncio de muitas perguntas que surgem naturalmente é espantoso e nos priva de outras informações, como a do destino de Pimienta e outras personagens.

Em suma: toda vez que María de Regla tenta usar suas informações, espécie de poder para obter vantagens para si ou para seus próximos, falha ou alcança seu objetivo muito parcialmente. Somente em uma passagem em toda a obra goza de certos privilégios: é quando amamenta Adela. Nas palavras de Civantos:

De manera que el amor maternal de doña Rosa hace que su posición dominante en 
cuanto a María de Regla sea superada por una de la dependencia. La nodriza adquiere ciertos poderes: no puede ser castigada, ni puede ser cambiada por otra. Al convertirse la esclava en ama de leche desplaza algunos de los poderes inmediatos del ama de esclavos (op. cit: 507).

Assim, ao possuir um certo status como ama de leite, embora temporário, sabe que enquanto durar a lactância de Adela, nada lhe acontecerá. Sabe, inclusive, sobre a paternidade de Cecilia e, por isso, pensa estar relativamente segura. Triste engano. Terminada a lactância, é desterrada e falhará amiúde ao tentar sair do engenho. A explicação é simples. Trata-se de uma escrava e esses só teriam alguma proteção garantida por lei contra os abusos de seus amos muitos anos depois da época retratada por Villaverde. A tal respeito Barros y Prado (op. cit.) esclarece que os escravos possuíam alguns direitos, mas isso só a partir da década de $1860^{21}$.

Desse modo, não obtém nada do que desejara, isto é, salvar seu marido da prisão ou conseguir sua liberdade. Tampouco atua positivamente na intenção de convencer Don Cándido e Leonardo a ajudarem a sair do engenho. Suas palavras lhes são inócuas porque jamais produzem algum resultado. Como exemplo, cito mais uma vez seu pedido para falar com o pai ou o filho estando no engenho, mas cuja resposta fora o silêncio: " - Vinieron unas Pascuas el amo y el niño Leonardo [ao engenho La Tinaja], mas ninguno de los dos quisieron verme ní oirme tampoco" (VILLAVERDE, 1981, p. 316). Nem sua posição privilegiada de ama de leite lhe valerá algo em seu futuro.

Para concluir, tentarei sintetizar algumas ações de María de Regla com o objetivo de amenizar sua dramática situação.

Algumas dessas ações têm êxito, outras não. As do último tipo referem-se às ações da escrava sobre sua ama. No que tange ao benefício para si, o resultado é quase nulo, mas não inócuo para outras personagens, pois efetivamente desencadearão uma série de conseqüências: Doña Rosa intervirá tentando separar Leonardo de Cecília, sabendo-o agora pai e tio consanguíneo de sua filha; essa separação desperta em Cecilia um estado de ânimo até então desconhecido para ela: passa de ovelha a leão; isso fará com que ela convença a José Pimienta, velho amigo, mas sobretudo apaixonado por Cecilia desde há muito tempo a impedir o casamento. Sua paixão é tal que, apesar de saber que Cecilia já é mãe e apaixonada por Leonardo, não hesitará em assassinar o primogênito dos Gamboa, mas o assassinato não faz com que a história termine aí. Dessa morte, Doña Rosa fará de tudo para punir Cecilia. Esse assassinato convence definitivamente Isabel Ilincheta internar-se em um mosteiro: "Por lo que hace a Isabel Ilincheta, desengañada de que no encontraría la quietud del alma en la sociedad dentro de la cual le tocó nacer, se retiró al convento de las monjas Teresas o Carmelitas, y allí profesó al cabo de un año de noviciado (VILLAVERDE, 1981, p. 403) 22.

Quanto à ação do primeiro tipo, somente à Adela María de Regla consegue demover a fim de obter alguma vantagem para si e só estando próxima à menina. Mas seu benefício é 
parcial, pois a ama continua escrava em Havana trabalhando como vendedora de carne pelas ruas dessa cidade.

Ainda assim, poderíamos nos perguntar se María de Regla alcançou sua tão esperada alforria $^{23}$. Nas palavras de Civantos (op. cit.)

Tanto Dionisio como María de Regla son destinados a la creación de un sistema de circulación más regular [María de Regla, como sabemos, vende carne pelas ruas de Havana]. Un movimiento más controlado, pero aparentemente más abierto, parece ofrecer la forma de apaciguar el deseo de imponer límites, de definir identidades, en un momento de cambio en Cuba. (p. 518).

A citação de Civantos refere-se à nova designação de María de Regla: vendedora de carne pelas ruas de Havana ${ }^{24}$. No entanto, não temos certeza se a escrava conseguiu o que desejava.

Outro fato que nos chama a atenção é que foram necessários os capítulos VIII e IX (p. 301-27) da Terceira Parte do romance para que María de Regla conseguisse influir parcialmente sobre sua ama. Toda sua vida, desde que vive na cidade de Jaruco até os anos que passa no engenho La Tinaja é pormenorizadamente contada. No entanto, bastou um parágrafo de cinco linhas no Capítulo VII do livro, o último, para que desencadeasse uma série de ações. É importante observar que do arranjo do casamento de Leonardo, o preparo das bodas, seu assassinato, a apuração dos fatos, o julgamento de Cecilia, sua prisão, o encontro com sua mãe moribunda no mesmo hospital haveria de passar um bom tempo. Mas tudo é sintetizado em cinco linhas pelo narrador. Portanto, o que interessa à sociedade na qual estão inseridas essas personagens vale muito mais a história dos criollos que o sofrimento dos escravos ou da população menos favorecida economicamente. Prova disso é a pobreza material de Seña Josefa e sua neta, Cecilia. Em parte alguma da obra vemos Don Cándido as ajudar efetivamente. Tudo que faz é dar uma certa quantia em dinheiro apenas para mantê-las vivas, nada mais. Também vemos a pobreza material do músico Pimienta e sua irmã, Nemesia. Da mesma maneira, assistimos a inúmeros personagens negros ou mulatos que não estão em condições socioeconômicas favoráveis. Em contrapartida, os brancos muitas vezes estão bem situados na sociedade havanesa retratada por Villaverde.

Enfim, quanto à sua intenção de convencer Don Cándido e Leonardo sobre seu sofrimento no engenho, já o vimos, será nula. É que para esses, perder somente um escravo era o mesmo que nada (por exemplo, quando da notícia do suicídio do escravo Pedro Carabalí, Don Cándido desdenha: “ßBa! Más ha perdido él que yo" (VILLAVERDE, 1981, p. 296). Também, quando se refere aos negros, profere inúmeras expressões como "Sacos de carbón” ou emite juízos como "Los negros a veces se empeñan en que los azoten y fuerza es darle gusto o se expone uno a que se le vayan a las barbas." (VILLAVERDE, 1981, p. 288).

Para Leonardo, María de Regla lhe era insuportável: 
El primer paso dado [isto é, quando nasceu a filha de Leonardo] fue el de solicitar los servicios de María de Regla, aquella enfermera del ingenio de La Tinaja, cuya astucia y talento la madre [Doña Rosa] y el hijo [Leonardo] conocían de consuno, a pesar de la ojeriza que la miraban (VILLAVERDE, 1981, p. 394).

Portanto, de ama de leite de Cecilia, Dolores e Adela, passando por privações e sofrimentos da mais variada ordem (como a proibição de amamentar sua própria filha e o desterro ao engenho La Tinaja), sua estratégia em voltar à cidade de Havana, sua nova vida ali primeiramente como vendedora de carne pela ruas dessa cidade e após como babá da filha de Leonardo e, por fim, a revelação que dá à Doña Rosa sobre a paternidade de Cecilia Valdés, podemos concluir que María de Regla é uma personagem de elevada complexidade não só psicológica, mas também para o desenvolvimento da própria história de Villaverde. Sem ela, dificilmente poderíamos imaginar o romance tal qual nos é apresentado. Desse modo, considero María de Regla como uma das protagonistas deste intrigante romance de Villaverde.

\section{A respeito das ações de Doña Rosa}

Nome completo: Rosa Sandoval de Gamboa. Isso nos é dado a conhecer somente no Capítulo XII da Primeira Parte. No que se refere às personagens principais, geralmente Villaverde apresenta aos poucos suas características, inclusive seus nomes. Como hábil escritor, não nos pinta de uma só vez cada protagonista. Sua estratégia consiste em nos apresentar ao longo da história de que modo é cada "ator" de seu romance. Isso tem especial relevância na obra, pois vamos construindo a cada passo como é na realidade cada individuo. Tal fato vale também para Doña Rosa. No Capítulo II da Primeira Parte, Villaverde nos informa não o nome da matriarca, mas a uma "señora algo gruesa, vestida com mucho aseo, que estaba arrellanada en un ancho sillón y descansaba los pies en un escabel” (VILLAVERDE, 1981, p. 18). E mais adiante, no Capítulo VII, o narrador nos dá a conhecer seu pré-nome em uma admoestação de Don Cándido: “ - Rosa, tus mamanteos van a perder a ese muchacho [a Leonardo].” (VILLAVERDE, 1981, p. 54).

Interessante personagem, Doña Rosa também desempenha papel fundamental na obra. Filha de ricos fazendeiros, herdou-lhes grande fortuna e casou-se com Don Cándido cuja posição sócio-econômica era então bem inferior a dela. Possui muitos escravos, tanto na cidade de Havana, onde mora, como no engenho La Tinaja, no interior, também herança de seus pais (VILLAVERDE, p. 1981: loc. cit.).

Sua maior preocupação é o bem-estar de seu filho, Leonardo. Outra preocupação que lhe ocupa em toda a história é a fidelidade de seu marido. Sempre desconfiou do episódio em que Don Cándido teve grande participação, qual seja, o da amamentação de Cecilia Valdés. A ela, jamais the foi convincente o argumento de seu marido que estaria encobrindo a 
paternidade de um amigo seu. Quando da descoberta da falsa história da amamentação de Cecilia revelada pelo médico Don Montes de Oca, no Capítulo XIII da Segunda Parte, a matriarca da família se convence de dita infidelidade, embora não tenha provas materiais. Por esse motivo, passa a mimar ainda mais a seu filho e, em contrapartida, odeia seu marido e lhe redobra o ódio à María de Regla.

Prova de seu zelo desmedido por Leonardo constata-se no Capítulo XII da Primeira Parte. Seu filho quer um novo relógio importado da Suíça O preço: dezoito onças de ouro. Em princípio, Leonardo dissimula seu interesse: “ - No creas que te voy a pedir.” [O relógio à sua mãe] (...) "Entretanto Leonardo fingía no advertir la actitud abstraída de su madre, ni dar indicios de arrepentimiento por el embarazo en que le había puesto con sus antojadizas indicaciones.”25 . Após longa discussão, a matriarca cede e mais tarde o presenteia enquanto esse fingia dormir, pois efetivamente Doña Rosa não tem coragem de pedir a Leonardo que guardasse as meias onças de ouro que recebia dela mesma a cada dia: “¡Pobrecito! - exclamó en tono casi audible - ¿Por qué había yo de privarle de nada cuando está en la edad de gozar y divertirse? Goza y diviértete, pues...” (VILLAVERDE, 1981, p. 99). É que para o amante de Cecilia, ter paciência, guardar dinheiro, planejar minimamente o futuro não condizem com seu temperamento, pois sempre foi mimado por sua mãe e é por isso que todos os seus desejos têm de ser satisfeitos no mesmo instante.

E não somente aos pedidos materiais Doña Rosa é condescendente com seu filho. Suas atitudes, por mais suspeitas que sejam, sempre são vistas como algo natural ou até recomendável. Por exemplo: no Capítulo X da Segunda Parte, quando Leonardo sai às escondidas para um encontro secreto com Cecilia, mas é descoberto por Don Cándido, esse, colérico, diz a sua esposa que seu filho iria fazer alguma coisa ruim, mas a matriarca lhe responde: “ - Quizás ha ido a tomar el fresco, quizás ha querido darte gusto levantándose de madrugada. No hay razón para sospechar nada malo” (VILLAVERDE, 1981, p. 180).

Assim, ao aquiescer aos caprichos de Leonardo, Doña Rosa dá uma espécie de livre conduto a seu filho. Também quando age para enganar Don Cándido, geralmente conta com a ajuda de Leonardo. Há, dessa forma, uma espécie de cumplicidade recíproca entre mãe e filho. Essa é uma das características que é evidente à matriarca.

Se Doña Rosa é indulgente com Leonardo, em contrapartida, é implacável com María de Regla. E embora não possua as informações que possui sua escrava, tem, como rica criolla, poder para agir grandemente, seja à socapa de seu marido, seja de modo claro.

Importante atentarmos ao fato da simultaneidade das ações nesse romance. Em diversas passagens, muitos fatos ocorrem ao mesmo tempo, como por exemplo, do indulto que dá Doña Rosa a muitos escravos castigados por D. Liborio no Capítulo VI da Terceira Parte enquanto Pedro Carabalí comete suicídio (informação dada no capítulo seguinte, mas cujo tempo da ação se dá no Capítulo VI). Com relação à María de Regla, o rancor que lhe 
guarda Doña Rosa cresce-lhe à medida que vão aumentado as evidências sobre a paternidade de Cecilia reveladas pelo médico Montes de Oca (VILLAVERDE, 1981, p. 201). Estando no engenho, após o referido perdão aos escravos capturados, a única pessoa que não é perdoada é María de Regla. Aos primeiros pedidos de Adela: “ - No, no. Ella no merece perdón... Tampoco se ha dignado pedírmelo." Sobre isso, o narrador comenta: "Cambió doña Rosa de repente de semblante y de actitud, pasando del fervor piadoso a la seriedad y... a la ira." (VILLAVERDE, 1981, p. 294).

O problema da ira de Doña Rosa com María de Regla se apresenta de modo ambíguo no romance. Não sabemos ao certo se a matriarca odeia sua escrava pelo fato de amamentar a uma menina que talvez fosse filha de seu marido, ou se pelo fato de sua ama de leite a ter desobedecido quando da amamentação de Adela. Talvez seja a soma dos dois. Mas um fato é evidente. Na trama do romance, devido a seu preconceito com relação aos escravos - fato comum a muitas pessoas na época - Doña Rosa em momento algum tenta angariar a simpatia de sua escrava. Tudo que sabe fazer é castigá-la. Se, em princípio, não a pune devido à suposta desobediência da amamentação dos bebês, em momento posterior o fará com todo rigor. Mais uma vez, Civantos (op. cit.) informa:

Este arreglo [o da amamentação de Cecilia] crea "celos" y "fuertes sospechas" por parte de Doña Rosa, las cuales desahoga cuando María de Regla ha cometido otro delito más concreto (la doble lactancia) y la destierra al ingenio después de cumplirse su encargo como nodriza de Adela" (VILLAVERDE, 1981, p. 509).”

\section{CONSIDERAÇÕES FINAIS}

Dada a inépcia da matriarca desde o início do romance, somente por acaso suas suspeitas com relação à paternidade de Cecilia Valdés serão confirmadas. A primeira, como vimos, com o médico Montes de Oca. E, por fim, será preciso a circunstância excepcional de Dionisio preso para que a escrava revele-lhe a verdade à sua ama .

Desse modo, seria interessante confrontarmos a densidade psicológica das duas personagens. Enquanto Doña Rosa, dado seu preconceito, somente sabe castigar à María de Regla e ser cega aos vícios de seu filho (ou como prefere dizer Don Cándido “ - Si de propósito te pusieras, Rosa, a perder el muchacho, me parece que no lo harías mejor" (VILLAVERDE, 1981, p. 208), María de Regla, dada sua condição desfavorável, tem de lançar mão dos mais requintados argumentos para convencer sua ama e todas as mulheres (quando da visita no engenho) da injustiça de sua punição. Ganha, com isso, densidade psicológica que não vemos em sua ama. Mas, como vimos acima, essa operação terá um efeito muito reduzido, ao menos no início, dada a condição sócio-política de Cuba nessa época. Portanto, Doña Rosa tem poder para resolver suas suspeitas, mas não sabe usá-lo. Poderíamos nos perguntar ainda se, para ela, valeria à pena a alforria de seus escravos Dionisio e sua esposa, essa intragávela 
ela, em troca de informações verídicas sobre a paternidade de Cecilia Valdés.

María de Regla, em contrapartida, tem a informação de que tanto necessita sua ama, mas só irá revelá-la à matriarca no fim do romance, dada, mais uma vez, à inépcia de Doña Rosa. 
1. Ed. Ayacucho. Caracas: 1981. Disponível em www.bibliotecaayacucho.gob.ve Último acesso em 30/11/2015; 12:30h. Doravante, todas as referências neste trabalho pertencem a esta edição.

2. Por mais de quarenta anos esta obra seria trabalhada e (re)conceitualizada pelo autor, às vezes, por longos períodos "descansando", pois dada a vida atribulada de Villaverde e a complexidade da obra, mencionada na introdução de seu romance, não lhe foi possível tratá-la com a atenção necessária: "...llevé vida muy activa y agitada, ajena por demás a los estudios y trabajos sedentarios.” (...) “...no me concedieron ánimo ni vagar para entregarme a la obra larga...” p. 45.

3. Que "parece" não saber sobre o parentesco de Cecilia. O verbo vai entre aspas porque Cecilia é muito parecida com a irmã caçula de Leonardo, Adela. Tal fato se percebe no Capítulo XII da Segunda Parte, quando Isabel, a pretendente de Leonardo para o casamento, pensa ver Adela quando na verdade vê Cecilia.

4. Como observa Rita de Maeseneer em "Celebrar, tragar, amamantar lo cubano: los contextos culinarios en Cecilia Valdés de Cirilo Villaverde", Villaverde faz com que María de Regla narre a história para o leitor no lugar do próprio narrador, ou o artigo de Roberto González Echevarría, "España en Cecilia Valdés" em que é feita a mesma observação.

5. Característica interessante nessa obra é a liberdade que possuem algumas personagens para tomar determinadas decisões: D. Liborio, capataz de La Tinaja, tem a permissão de Don Cándido para açoitar os escravos desse engenho quando bem lhe aprouver, embora Doña Rosa os desaprove, com exceção aos castigos infligidos à María de Regla; Leonardo pode espancar seus criados quando lhe apetecer e visitar Cecilia Valdés, fatos aprovados por sua mãe e reprovados por seu pai, etc. Vemos, portanto, uma espécie de assimetria nas ações de algumas personagens nesta obra.

6. Como se sabe, o leite de Doña Rosa secara nos primeiros dias de vida da menina impossibilitando-a de amamentá-la porque "...por no sentirse ella en condiciones para desempeñar por entonces aquél, el más dulce de los deberes de madre” (VILLAVERDE, 1981, p. 172-3). Acrescenta-se a isso, a preciosa informação de Juan G. Gelpí a respeito dessa personagem: "María de Regla constituye una figura mediadora y transgresora. Les da el pecho a su propia hija negra Dolores, a la mulata Cecilia Valdés y a la hermana blanca de ésta, Adela Gamboa". "El discurso jerarquico en "Cecilia Valdes" In: Revista de Crítica Literaria Latinoamericana. Año 17, No. 34 (1991), p. 47-61 (esp. p. 52). O crítico ainda acrescenta outra importante informação: longe de unir as três raças (porque María de Regla amamenta à Adela (criolla), Cecilia (mulata) e Dolores (negra), Villaverde desfaz essa ilusão no final do romance porque, como sabemos, nada termina bem: Leonardo é assassinado, Cecilia é presa e María de Regla continua escrava pelo menos por um bom tempo. Também assim, Christina Civantos acrescenta que não somente María de Regla, mas grande parte das amas de leite nessa época eram figuras incômodas, um mal necessário: "Así y todo, por la mera existencia de la nodriza, María de Regla, persiste el espectro de la mala madre - la madre que no cumple con su deber sagrado". "Pechos de leche, oro y sangre: Las circulaciones del objeto y el sujeto en Cecilia 
Valdés". In: Revista Iberoamericana, Vol. LXXI, Núm. 211, Abril-Junio 2005, p. 505-19. Veremos mais adiante que não parece ser somente esse o motivo do ódio que sente Doña Rosa à sua escrava.

7. "El incesto y el mestizaje en Cecilia Valdés" In: Revista Iberoamericana: 2004, Vol. LXX, no 206, p. 87-101. É importante acrescentar, então, que a pena imposta à María de Regla por Doña Rosa equivalia a de um homicídio. Veja, por exemplo, seu marido Dionisio o qual, após assassinar a Tondá, espécie de caçador de recompensas para capturar escravos em Havana, "El tribunal le condenó a diez [años] de cadena" para a composição de ruas (VILLAVERDE, 1981, p. 403).

8. Revista Iberoamericana, Vol. LXXI, núm. 211. Abril-Junio 2005, 505-19.

9. Também é importante lembrar que a resposta de Doña Rosa às supostas provocações da escrava aos escravos e homens em La Tinaja era sempre a mesma: “ - Castigue a esa perra" (p. 316).

10. "Castigo que se le daba al esclavo, estando en posición este con la boca abajo, usando el mayoral o el contramayoral el látigo." Nota de Iván A. Schulman, na introdução da edição da Biblioteca Ayacucho (VILLAVERDE, 1981, p. 176).

11. Ironicamente seu nome indica aquele que tem a natureza emotiva, amável e condescendente.

12. Aqui vale lembrar Foucault em Vigiar e Punir. Nas primeiras páginas da obra, o filósofo menciona a questão do suplício para penas consideradas graves (como o parricídio) e praticada em fins do século XVIII e início do XIX. Essa modalidade de castigo foi sendo abolida aos poucos, optando-se por penas alternativas como a reclusão, por exemplo. Mas não parece ser o caso nos engenhos de açúcar em Cuba e no romance de Villaverde (e, ao que parece, de forma geral no continente americano). Na lógica dos Gamboa, qualquer delito dos escravos deveria ser castigado severamente, pois não fazia sentido para os senhores de engenho a reclusão de seus escravos uma vez que eles deveriam produzir, mesmo estando machucados.

13. Na nota número 15 do referido artigo, o autor aponta cinco ocorrências de aspas na fala da personagem em seu relato de dezesseis páginas (VILLAVERDE, 1981, p. 311-326)

\section{Disponível em www.youtube.com/watch?v $=\mathrm{BrhlXB} 4 \mathrm{xxZO}$.}

15. Procedimento muito semelhante ocorre à protagonista da única obra citada por Villaverde na introdução de Cecilia Valdés: La joven de la flecha de oro (1841). Paulina, a protagonista do romance, aceita casar-se com Cifuentes, trinta e três anos mais velho, por sugestão de sua mãe e suas irmãs. Após ser cerceada implacavelmente por seu marido, privando-a inclusive de assomar-se à janela, enlouquece e grita desesperadamente ao ouvir o nome de Cifuentes. Assim, parece ser algo comum em Villaverde o alto grau de suscetibilidade psicológica das filhas mais novas em seus romances.

16. "La primitiva Cecilia Valdés" In: Cuba en la UNESCO: Homenaje a Cirilo Villaverde. Marzo, 
17. Fica sugerido no romance que as filhas ricas e brancas também não escapariam dos preconceitos comuns à época. Vide, por exemplo, a referida passagem na qual Antonia ameaça castigar duramente ao cocheiro e escravo Aponte por este ter brigado com outro cocheiro após um acidente.

18. La Habana a mediados del siglo XIX. Madrid: Imprenta de la Ciudad Lineal, 1925, p. 113. O autor relata ainda: "Recuerdo haber oído varias veces en cuestiones, lanzar como insulto uno a otro la palabra mulato, y contestar el agraviado con mucho énfasis: Yo no soy mulato, yo soy Valdés" (BARRAS Y PRADO, 1925, p. 113-4).

19. In: Cuadernos de Literatura, no 31. Enero-Junio 2012.

20. Sabemos que Dionisio estava condenado, pois, anteriormente, no Capítulo V da quarta parte, o Alcaide havia aconselhado a Dom Cándido a renunciar a seu escravo e entregá-lo ao mando da lei (VILLAVERDE, 1981, p. 371) após ter ciência do assassinato de Dioniso frente a Tondá. Então, o representante da lei aconselha Don Cándido: "Se entiende en derecho entregar el esclavo a la noxa, al acto de la renuncia del dominio directo que sobre él tiene el amo, en favor del tribunal de justicia que le juzga por el delito o daño cometido." (VILLAVERDE, 1981, loc. cit.).

21. Esquematicamente, poderíamos dispor dos acontecimentos nessa ordem:

María de Regla $\rightarrow$ Adela. Resultado: não estando no engenho, Doña Rosa não cede. age sobre

Em La Tinaja: María de Regla $\rightarrow$ Adela.

$$
\text { age sobre }
$$

Resultado: Adela $\rightarrow$ Doña Rosa e María de Regla volta ainda como escrava à Havana. age sobre

Mas, com relação a Dionísio:

María de Regla $\rightarrow$ Doña Rosa. Resultado: Doña Rosa nada fará por Dionisio. age sobre

No entanto, de posse dessa informação: Doña Rosa $\rightarrow$ Leonardo e Isabel (casamento). age sobre O casamento, por sua vez, $\rightarrow$ age sobre

Então, Cecilia $\rightarrow$ Pimienta.

age sobre

Pimienta $\rightarrow$ Leonardo

age sobre (assassina-o).

Doña Rosa $\rightarrow$ Cecilia

age sobre (faz com que a aprisionem). 
22. "Si éste [o escravo] no está contento con su amo, la ley le concede un tiempo determinado para buscar otro; si quiere coartarse o empezar a redimir su cautiverio, la ley se lo concede también, obligando al amo a recibir cincuenta pesos (...) estando hoy prohibidos los castigos fuertes, y cualquier autoridad tiene derecho a impedirlos" (BARRAS Y PRADO, 1925, p. 1101). Mas essa informação vale somente a partir de 1864, época bem posterior ao do romance.

23. Uma mostra do desejo de María de Regla em obter a liberdade encontra-se no Capítulo VIII da Terceira parte quando do encontro com as filhas de Don Cándido: “iLa libertad! ¿Qué esclavo no la desea? Cada vez que oigo pierdo el juicio, sueño con ella de día y de noche, formo castillos, me veo en la Habana rodeada de mi marido y de mis hijos..." (VILLAVERDE, 1981, p. 316).

24. Com a nova "profissão", María de Regla ao menos teria como guardar algum dinheiro e comprar sua liberdade após alguns anos, fato comum a muitos escravos não só em Cuba, mas também no Brasil.

25. Podemos encontrar a mesma tópica em Memórias Póstumas de Brás Cubas, publicado um ano após a obra de Villaverde. Marcela, a amante do protagonista que dá nome ao romance, finge não querer uma jóia: "Assim foi que um dia, como eu não lhe pudesse dar certo colar, que ela vira num joalheiro, retorquiu-me que era um simples gracejo, que o nosso amor não precisava de tão vulgar estímulo. - Não lhe perdôo, se você fizer de mim essa triste idéia, concluiu ameaçando-me com o dedo." E, após presentear sua amante com a referida jóia: "Marcela teve primeiro um silêncio indignado; depois fez um gesto magnífico: tentou atirar o colar à rua. Eu retive-lhe o braço; pedi-lhe muito que não me fizesse tal desfeita, que ficasse com a jóia. Sorriu e ficou." Disponível em <www.domíniopublico.gov.br> pesquisa. (Último acesso em 10/07/2016; 20h:55min.). 
ARISTÓTELES. Poética. Trad. Eudoro de Souza. São Paulo: Abril Cultura, 1973.

BARRAS Y PRADO, A. La Habana a mediados del siglo XIX. Madrid: Imprenta de la Ciudad Lineal, 1925.

CIVANTOS, C. "Pechos de leche, oro y sangre: Las circulaciones del objeto y el sujeto en Cecilia Valdés”. In: Revista Iberoamericana. Vol LXXI, no 211, Abril-Junho 2005, p. 505-19.

FOUCAULT, M. Vigiar e punir: nascimento da prisão. Trad. Lígia M. Pondé Vassalo. Petrópolis. Ed. Vozes, 1977.

GELPÍ, J. G. "El discurso jerárquico en Cecilia Valdés". In: Revista de Crítica Literaria Latinoamericana, Ano 17, no 34, 1991. P. 47-61.

MONTELEONE, K. "El incesto y el mestizaje en Cecilia Valdés" In: Revista Iberoamericana. Vol. LXX, no 206, Janeiro-Março, 2004. P. 87-101.

VILLAVERDE, C. Cecilia Valdés o la loma del ángel. Caracas: Biblioteca Ayacucho, 1981 (edição on line disponível www.bibliotecayacucho.gob.ve).

"La primitiva Cecilia Valdés" In: Cuba en la UNESCO. Homenaje a Cirilo Villaverde. Havana: Março de 1964, anos 3-4-5. P. 232-51. 